\title{
Argyria In An Elderly Man
}

\author{
J Glenn, A Walker
}

\section{Citation}

J Glenn, A Walker. Argyria In An Elderly Man. The Internet Journal of Dermatology. 2001 Volume 1 Number 2.

\section{DOI: $\underline{10.5580 / \mathrm{d} 5 \mathrm{~d}}$}

\section{Abstract}

Argyria is caused by prolonged ingestion of silver salts or their application to mucous membranes.[1] This happens principally in sun-exposed areas as light aids in the conversion of silver. [2] Discoloration of mucous membranes and internal organs may also occur.[1] Aside from the cosmetic effect, argyria is of little physiologic consequence to the patient. It may, however, be confused with other conditions. We present the case of an elderly man with argyria whose skin color raised initial concerns of cyanosis.

\section{REPORT OF A CASE}

An 88-year-old white male farmer presented following treatment of a respiratory infection. Although he was in no apparent distress, he was initially thought to be cyanotic. Further examination revealed a slate-blue discoloration of the skin that was most prominent in sun exposed areas, mainly involving the face (Figure 1) and upper torso. 40 years earlier he had self-administered an intranasal silver nitrate solution for chronic sinusitis over a period of six years. The skin discoloration had appeared gradually and been most noticeable while he was actively using the silver nitrate solution, during which time the discoloration involved his entire skin surface. After discontinuing use of the solution, the discoloration faded except in areas of sun exposure.

\section{Figure 1}

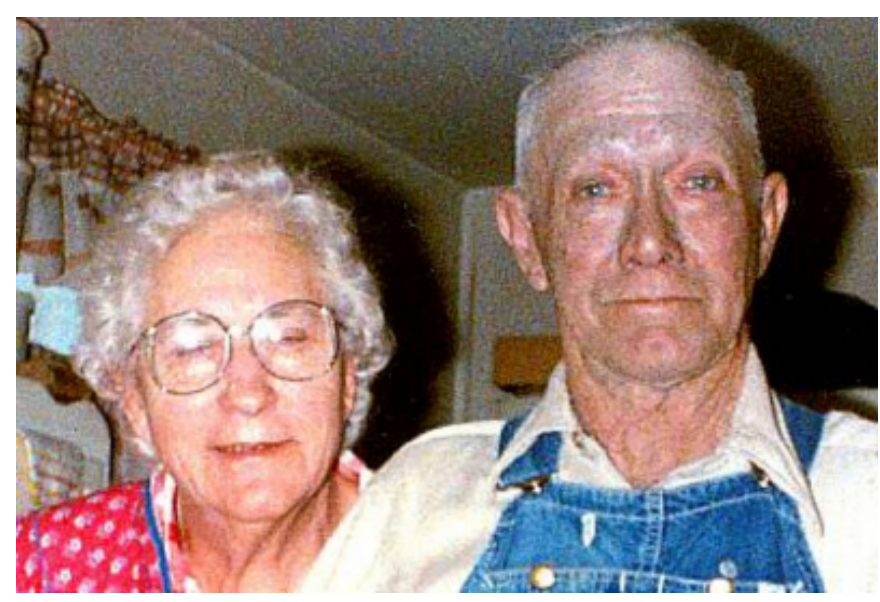

\section{DISCUSSION}

Clinically, argyria occurs when silver is deposited in its elemental, sulfide, or selenide form. Microscopically, silver granules are generally extracellular. They appear as irregular aggregates concentrated in the basal lamina of dermal sweat glands, and in association with the adventitia of hair follicles, sebaceous glands, capillaries, and nerves. $\left[{ }_{1,3}\right]$ Melanin is increased in the overlying basal cell layer suggesting that silver may promote its production. The combination of silver granules and the increased production of melanin accounts for the slate-blue discoloration of the skin.[1]

Similar pigmentation of sun-exposed skin is a recognized side effect of several drugs, including the antiarrhythmic amiodarone and gold therapy. The former drug is iodinated and accumulates in lipofuchsin granules within secondary lysosmes of dermal macrophages. Prolonged treatment of rheumatoid arthritis with parenteral gold salts can result in chrysiasis where gold particles are found intracellularly within dermal endothelial cells and macrophages. Our patient had no history of these medications.[1]

Hemochromatosis is as a very common genetic disorder. Here again, gray pigmentation is found in sun exposed areas and is thought due to exaggerated melanin production despite the coexisting accumulation of iron in the skin. Such patients, however, usually have other manifestations of hemochromatosis at the time of presentation, including diabetes mellitus and cirrhosis. Serum iron studies are helpful in establishing this diagnosis. [1] 
Congenital methemoglobinemia generally produces a lifelong, asymptomatic cyanosis due either to increased generation or inadequate reduction of methemoglobin in the circulation. Affected individuals do not exhibit the patchy distribution of pigmentation seen in our patient.

The therapeutic use of silver dates to 1647 when it was prescribed for the treatment of epilepsy. $\left[1,,_{2}, 4\right.$ Syphilis was treated with silver arsepenamine in the early 20th century and cold remedies contained colloidal silver proteins until the mid-20th century. [4] In 1939, Hill and Pillsbury documented 239 cases of argyria, most of which were due to oral or nasal application of silver nitrate. [2] Medicinalrelated cases of argyria have become rare due to the advent of antibiotics and related anti-microbial agents. Ophthalmic silver solutions are still used to treat ophthalmia neonatorum. Other topical silver-containing solutions are employed primarily for treatment of burn wounds or as cauterizing agents. Currently, silver preparations are not approved for over-the-counter use. Health food stores, however, actively promote silver formulations for a number of conditions. [4]

\section{CORRESPONDENCE TO}

Anna N. Walker, MD Department of Pathology Mercer University School of Medicine 1550 College Street Macon, GA 31207 Telephone: 478-301-4067 FAX: 478-301-5489

Email:walker_an@mercer.edu

\section{References}

1. Lever WF, Schaumburg-Lever G: Histopathology of the Skin. 7th edn. Philadelphia: J.B. Lippincott Company, 1990, pp1254-56.

2. Humphreys S, Routledge P: The toxicology of silver nitrate. Adverse Drug React Toxicol Rev 17:15-43, 1998. 3. Prescott RJ, Wells S: Systemic argyria. J Clin Pathol 47:556-7, 1994.

4. Fung, M.C., Bowen D.L. Silver products for medical indications: Risk-benefit assessment. Clin Toxicol 34:19-26,1996. 


\section{Author Information}

Joshua B Glenn

Mercer University School of Medicine

Anna N Walker, MD

Department of Pathology, Mercer University School of Medicine 